\title{
How Health Relationship Management Services (HRMS) Benefits Telemedicine
}

\author{
Nik Tehrani, PhD \\ DynoSense Academy, CA, USA
}

\begin{abstract}
Yousef lives in a remote area of Pakistan with limited access to healthcare. As a result of not having proper disagnoses, care or medication, Yousef's hypertension has begun to damage his heart. A major barrier for Yousef getting good healthcare is the long distance between the village and quality care hospitals that are miles away, so he becomes a patient at the local village quack clinic that is not qualified to treat Yousef's complicated health condition. Telemedicine in the form of Health Relationship Management Services (HRMS) has come to the village, so now, Yousef can receive proper diagnoses, advice, medication and treatment without having to travel afar. Telemedicine allows specialists that are miles away to access Yousef's personal health data to make meaningful decisions about his healthcare. (Int J Biomed. 2016;6(2):146-147.).
\end{abstract}

Key Words: telemedicine $\bullet$ health relationship management services $\bullet$ health condition $\bullet$ healthcare

Yousef is a 60 -year old man living in a very small village in the Baluchistan province of Pakistan known as Sofia. He is the only income provider for his family of a wife and two daughters. Yousef has been suffering from hypertension for many years, but he has never been able to get the proper treatment for it due to living in the remote mountainous region in Pakistan. The health services in Sofia are low-quality, while quality health services are located in the nearest city almost $100 \mathrm{~km}$ away. Initially, Yousef went to the local health clinic to cure his hypertension because he lacked transportation and could not afford the quality care in distant healthcare facilities. Unfortunaely, the clinic was staffed by untrained and underexperienced people. As a result of receiving erroneous healthcare in his village, Yousef's health was seriously damaged and propelled his hypertension into a full-blown heart problem. Yousef did finally visit the nearest government hospital, but he was told that the hospital was not equipped with the necessary technology or health specialists needed to deal with his acute health condition. Yousef was told that he needed further assessment by a heart specialist, but the nearest one was inaccessible due to to the remoteness of the village. Soon, his daughters heard that there was something new being introduced in their village clinic that could help their beloved father. They were informed that the clinic was incorporating Health Relationship Management Services (HRMS), which is

Corresponding author: Nik Tehrani, PhD. DynoSense Academy, CA, USA.E-mail: ntehrani@dynosense.com an advanced form of telemedicine services..$^{[1,2]}$ Yousef's main barrier that has kept him from getting appropriate quality healthcare is the long distance between his village and good hospitals and qualified specialists. Now, with telemedicine, Yousef can get expert long-distance advice from professionals who can recommend the proper treatment for his condition.

Now that Yousef's issue is resolved, he no longer needs to travel a long way to the main city for health services. With quality healthcare so close to home, Yousef is able to visit the local hospital for HRMS to care for his condition. A care specialist is assigned to Yousef's case for diagnosis and treatment through telemedicine, which offers medical services to remote locations. After having the proper professional medical care, Yousef is now experiencing a different lifestyle. Through the use of a health monitoring system that captures his personal health data, Yousef now can immediately know the result of his health metrics. Yousef's health data is collected daily and stored in the cloud where it is restructured by analytics software for evaluation. This analyzed data, in an aggregated form, is represented by an individualized health scoring and demographic grading system. The meaningful data is analyzed by the heart specialist who monitors Yousef's health condition. In essence, the health data captured by the system each day is measured against Yousef's health database, and if a change should occur, his care-provider is immediately alerted and can now access his health information in order to recommend treatment and lifestyle changes for optimum health. The care specialist discussed Yousef's case with physicians at 
the provincial hospital many miles away, who then diagnosed Yousef with chronic hypertension and diabetes. As a result, the care specialist has prescribed a different course of treatment plan for Yousef. Now, Yousef and his family are very satisfied with HRMS benefits he receives at the local clinic. Yousef's daughters are relieved that their father's life is in safe hands, and are pleased that they can now communicate with the specialist remotely, due to availability of the telemedicine treatment.

The stigma that was once associated with the rural areas that lacked quality health services are just a dim memory, and the dream of quality healthcare in remote areas is now a reality. At the outset, Yousef and his family were given the basic information about HRMS: what it consists of, and every step that is involved. It was very comforting for the family to know the status of Yousef's condition immediately in their own home without having to travel $100 \mathrm{~km}$ for the treatment. It was very educational and a relief for the family to know that solutions to many chronic medical health conditions are now available to them in their own locale. Now, the last step is to continue using the system for continous monitoring of Yousef's health condition. This is the real benefit of this advanced telemedicine service. Day-by-day, Yousef's health has improved; he started taking his prescribed medications on a regular basis to treat his chronic condition. The results are apparent, and he has resumed his business in his village. The medical care that once was out of reach to remote villagers like Yousef is now within reach. ${ }^{[3]}$

Yousef's family was astonished at how a physician a hundred miles away could prove to be so helpful by connecting to a telemedicine system in their own village. They spread awareness to the other villagers, so that they, too, can also improve their health and their relatives simply just by availing the services of HRMS. As a result, the local villagers patronize the local hospital where the HRMS system was put in place by health officials. In turn, many people have been diagnosed with chronic conditions that were once misdiagnosed by the unexperienced set of so-called doctors in the village. Telemedicine made such a positive impact on the inhabitants in the village, that it is a widely-accepted fact that the HRMS benefits are effective. Patients can be in touch with any specialist thousands of miles away, while in their own homes or village. Health Relationship Management Services helped Yousef and his local villagers by resolving their health problems. ${ }^{[4]}$ Yousef's story, and others like his, could be made possible in actuality with the advent of advanced telemedicine devices and Health Relationship Management Services (HRMS).

\section{References}

1. Tehrani N. Health Relationship Management Services (HRMS): A new healthcare paradigm using the 5Rs. Int J Biomed. 2016; 6(1):87-89. doi: 10.21103/Article6(1)_CC1

2. Kahn JM.Virtual visits--confronting the challenges of telemedicine. N Engl J Med. 2015 Apr 30; 372(18):1684-5.

3. Rogove HJ, McArthur D, Demaerschalk BM, Vespa PM. Barriers to telemedicine: survey of current users in acute care units. Telemed J E Health. 2012 Jan-Feb;18(1):48-53. doi: 10.1089/tmj.2011.0071.

4. Levin K, Madsen JR, Petersen I, Wanscher CE, Hangaard J. Telemedicine diabetes consultations are cost-effective, and effects on essential diabetes treatment parameters are similar to conventional treatment: 7-year results from the Svendborg Telemedicine Diabetes Project. J Diabetes Sci Technol. 2013 May 1;7(3):587-95. 